\title{
Research on New Media Protection for Intangible Cultural Heritage from the Perspective of Communication*
}

\author{
Xuemin Bao \\ Heihe University \\ Heihe, China 1634300
}

\author{
Shengnan $\mathrm{Yu}$ \\ Heihe University \\ Heihe, China 1634300
}

\begin{abstract}
The development of informatization in the new media era provides new methods and ways for the dissemination of intangible cultural heritage. This paper is guided by the perspective of communication to explore the new media protection of the intangible cultural heritage from the four aspects of distributor, communication value, media and audience, so as to help preserve the intangible cultural heritage for a long time.
\end{abstract}

Keywords-intangible cultural heritage; new media protection; communication media

\section{INTRODUCTION}

Intangible cultural heritage refers to various traditional cultural expressions (such as folk activities, performing arts, traditional knowledge and skills, and related instruments, objects, handicrafts, etc.) and cultural space that are inherited by generations and closely related to the lives of the people. [1] It is a human-oriented living cultural heritage, mainly imparting skills, experience, etc., and mainly based on interpersonal communication, but in the actual process of communication, it is limited by time and space, and even faces loss. In recent years, with the development of the network and the continuous advancement of modern science and technology, people have begun to explore new media protection for intangible cultural heritage. It has become very urgent to use digital technologies such as virtual technology and computer technology for widespread dissemination of intangible culture heritage.

\section{COMMUNICATOR: MULTI-DIMENSIONAL IMPROVEMENT OF COMMUNICATION ABILITY}

In 1948, Lasswell clearly proposed the five basic elements of communication. For a communicator, the dissemination of intangible cultural heritage is mainly divided into two categories, the one is the museum and exhibition hall that stores non-legacy materials, and the other one is the inheritor

*Fund: [This article is the research achievement of "Study on the Digital Media Communication Strategy of Intangible Cultural Heritage in Heilongiiang Province under the New Media Environment" of the Heilongiiang Provincial Education Department's research program for scientific research and special innovation projects (18KYYWFCXZ05)]. of traditional craftsmen, and the two can improve communication ability from the following aspects.

First, in the exhibition of intangible cultural heritage, libraries and exhibition halls can not only present the materials stored in the museum through multimedia technology (such as video production, photo display, experience scenes, etc.), but also build digital non-legacy museum and seek for a combination of user experience and communication subject. Second, the inheritors should learn the means of communication of new media to use the current short video, WeChat platform, H5, webcast APP and other forms to pass traditional craftsmanship to young people. This form of communication can not only interact with users from time to time, but also form a secondary spread, maximizing the effect of communication.

\section{Spreading VAlue: Creating Value Space From MULTIPLE ANGLES}

The dissemination value of new media refers to achieve the integrity of intangible data preservation and the inheritance of craft skills of the intangible cultural heritage in the process of dissemination through the utilization of virtual technology, simulation technology and new media means to protect its multi-dimensional value space.

\section{A. Conductive to the Preservation of the Integrity of Intangible Cultural Heritage Materials}

As a gem in the splendid culture of the Chinese nation, intangible cultural heritage has rich and unique cultural connotations, mainly related to oral traditions, folk activities and ceremonial festivals, traditional handicrafts, etc., but with the advancement of time as well as science and technology, non-material cultural heritage is slowly disappearing from the public's vision. New media technology provides new ideas for the protection of intangible cultural heritage. With big data and virtual simulation as technical support, through the restoration and reappearance of intangible cultural heritage scenes and data, by summarizing and analyzing the laws in the process of evolution, objective data will be obtained, which provides integrated information for the protection of intangible cultural heritage. 


\section{B. Conductive to the Economic Value Creation of Intangible Cultural Heritage}

The protection of intangible cultural heritage has always been strongly supported by the state and the government. Although the government has stepped up its economic and policy tilts to the non-legacy areas every year, the most fundamental thing is that the area must transform and innovate the value of non-legacy itself. The arrival of the digital age provides a certain opportunity for the development of intangible cultural heritage. While protecting the local intangible cultural heritage, it will also promote the development of local tourism economy. On the one hand, the material cultural heritage place establishes a digital museum to reappear the history of intangible cultural heritage through collection and coding so that realistic two-dimensional scenes can be simulated, and the scenes can be divided into interactive design somatosensory areas, virtual reality experience areas and other venues; on the other hand, it's necessary to establish a network communication platform based on the local intangible cultural heritage. The development of the two aspects can not only preserve the intangible cultural heritage for a long time, breaking through the geographical restrictions, but also promote the economic development of local ethnic minorities and form a sustainable cycle.

\section{Conductive to Carrying Forward the Skills and Techniques of Intangible Cultural Heritage Craftsmen}

Intangible cultural heritage involves the inheritance of traditional craftsmanship skills. This method mainly means passing the skills down from generation to generation in the way of "masters-to-apprentices". If the ordinary people want to learn, books, videos or following traditional craftsmen are available for them. But today, in the digital age, the skills and techniques of intangible cultural heritage are spread through the forms that young people like to see and hear, which brings better effects of communication. For example, on the one hand, traditional craftsmen can use their live broadcast platform to display and interact with netizens, and on the other hand, they can use the form of new media such as WeChat and $\mathrm{H} 5$ to communicate interactively. This new media communication keeps the information integrity well while enhancing the interaction with the audience, allowing the audience to truly feel the charm of intangible cultural heritage. Generally speaking, new media communication has an important significance for the inheritance of national culture.

\section{Media: MUlTi-FACETED COMMUNICATION PlatFoRM INNOVATION}

The famous Canadian communication scientist McLuhan put forward the theory of "media as the message" in the book Understanding Media. He believes that media is not only a tool for communication, but also an extension of the sensory parts of human body. From the theoretical level, beyond a part of people's body, more importantly, the media penetrates into every aspect of people's lives, especially nowadays, it has entered the era of network communication. According to the data, as of the end of June 2017, the number of Internet users in China has reached 751 million, of which the scale of mobile Internet users has reached 724 million, accounting for $96.3 \%$. Material cultural heritage is the country's rich cultural resources and the mass media have the responsibility and obligation to inherit the intangible cultural heritage, which requires efforts in the media.

\section{A. Immersive Communication - Virtual Reality Technology to Show Non-legacy}

Today, digital age has changed the way people live and behave. As Negroponte said in the book Digital Survival: "calculations are no longer only related to computers, it determines our survival" [2], and with the advent of technology, the dissemination of intangible cultural heritage has begun to be presented through the technology of new media. Virtual reality technology is an emerging network technology that dates back to the United States in the 1950s. Mainly by panoramic shooting and 3D animation technology, VR technology can simulate human features. Visitors are allowed to experience the immersive propagation of the virtual environment by wearing a certain device, and achieve a full range of sensory experience of vision, hearing and touch through real-time interaction with the scene. The environment of virtual space to showcase intangible cultural heritage can transform intangible culture into visual, audible data and lakes, enabling users to interact with the virtual world and enhance the user experience.

The combination of virtual reality technology and intangible cultural heritage reconstructs the scenes of historical humanities, folk customs and natural features of the original place, and realizes full-time display of 360-degree, all-season or re-emergence of historical scenes and human events. Regardless of locations, the audience can achieve virtual interaction with the intangible cultural heritage by simply opening the phone and downloading the app or retrieving relevant information. This new media interaction breaks the time and space constraints, enabling the sharing of resources.

At present, the intangible cultural heritage inheritance under virtual reality technology has been carried out throughout the country. As the largest "mobile" cultural in Beijing, non-legacy project, in combination with VR technology, AR cloisonne digital creation, VR ancient architectural scene crossing, holographic courtyard building skills, Square Zun with All Sides of national ceremony etc. provides an immersive experience for the audience, allowing them to interact on a virtual and realistic level. For example, on the AR station, the audience can simulate the complete process of cloisonne from embryo making to firing according to the corresponding prompts, allowing the experiencer to experience the production process of intangible cultural heritage, while feeling larruping non-legacy charm from the visual, auditory and tactile experiences.

\section{B. Interactive Communication - Micro-scene to Show Non- legacy}

Micro-scene is a new content display form that is edited by Html5 encoding technology. It is specially designed for 
mobile terminals. With responsive page matching technology, it can be smartly and automatically adjusted in different mobile terminals. [3] In the H5 page, audio, text, images, animation and other media elements can be integrated, and the three-dimensional scene can be set. It has interactive functions such as links and messages, mainly involving the applications of invitations, voting and drawing.

The dissemination of micro-scene is mainly realized through the WeChat platform. The two have good compatibility. The spread of WeChat and the amount of user forwarding can be used to form multiple transmissions, and the intangible cultural heritage, inheritor stories, non-legacy activities, etc. shall be edited and displayed. New media technology helps to achieve the unification of sound, animation and content, forming a unified visual and auditory and increasing the sense of presence and immersion. In this respect, it's necessary to learn from the more successful cases in the cultural field, such as the traditional culture displayed by combining with the new media technology. The cooperation result of Crossing the Forbidden City H5 jointly launched by The Imperial Palace and Tencent Vedio displays in the respective of crossing the Imperial Palace in the way of rap. The magical and contrast style has firmly grasped the audience's attention and the number of views has reached 3.47 million. Meanwhile, the Forbidden City Cultural Service Center also launched the first children's app "Emperor's Day", which enhanced the interaction with users. Under the leadership of the little lion outside the Qianqing Men, the user can learn that the Qing emperor how to spend the day through mini-games such as "silver prelibation" and "hit the target at every shot" to know about the Forbidden City culture and traditional culture. This form of communication can be applied to intangible cultural heritage. It's will be great significance of using $\mathrm{H} 5$ to set the figure of the inheritance story of intangible cultural heritage, then combining the process of making craft to display the sound and picture and forwarding the Wechat Moments to gain "likes" and so on to incorporate the innovation of intangible cultural heritage with new technologies. Only guided by the needs of users, the intangible cultural heritage items will be effectively and widely disseminated.

\section{Network Communication - the Form of Live Broadcast to Show Intangible Cultural Heritage}

Recently, webcasting has received much attention, and it has rapidly developed into a new Internet culture format. The data shows that as of December 2016, the number of online live broadcast users has reached 344 million, accounting for $47.1 \%$ of the total netizens. The number of online live broadcast platforms is close to 200 . The coverage of webcasts is pretty wide, which involves culture, games, education, entertainment, etc. In terms of live broadcast, users can also conduct personal live broadcasts, etc., and this form of webcast has entered the public's field of vision.

The traditional transmission of intangible cultural heritage is mainly interpersonal communication, featured by face-toface oral communication, but this method can only be used in close proximity and local area, and the current interpersonal communication can take the form of webcast. Although it cannot follow the way of face to face, spreading on the screen of mobile phones has broken the geographical restrictions, which not only allows more people to pay attention to the intangible cultural heritage, but also interacts with users in real time, enhancing the dissemination effect of intangible cultural heritage.

As one of the live broadcast platforms, the Pepper Platform successfully held "Inheritance, CraftsmanshipIntangible Cultural Heritage touring broadcast" in June 2017, mainly showing "Jade Carving", "Longquan Sword", "Ancient Fragrance Making", etc. The intangible cultural heritages have attracted more than 7 million netizens' attention, and have brought millions of sales orders for intangible cultural heritage craftsmen, enhancing the "selfhematopoietic" ability of the intangible cultural heritage industry. In the live broadcast, in addition to enjoying the intangible cultural heritage project through the broadcast, at the same time, the user combines the story behind the heritage to understand the craftsman Ma Rui's dedication to the dirty and tiring jade carving work, the hardship of Biyao, the inheritor of "Sichuan long mouth teapot", when she leaned the skills stealthily, so that young users have a new understanding of the intangible cultural heritage. At the same time, the interactive and real-time nature of the live broadcast to make a question-and-answer exchange inspires young users' passion to carry forward intangible cultural heritage.

At present, there are not many intangible cultural heritage + live broadcasts style in various places. As an emerging form of technology, webcasting can transform "intangible" and "cold" heritage through explanation and interaction, and transform non-material cultural resources in a way that young people accept, letting users be personally on the scene. For example, the inheritance of birch bark culture in Heilongjiang can be carried out in live broadcast form. Through the process of making birch bark on-site display, audience can understand the story behind the inheritor. This form is not only relatively low cost; at the same time, it will also activate the heritage in the needs of the people, so that the dissemination and inheritance of the non-legacy culture complement each other and form a good interaction.

\section{AUdiEnCE: MeEt USER's NeEDS IN A MUlTI-LEVEL} WAY

The theory of "use and satisfaction" in communication studies mainly refers to treating audience members as individuals with specific "needs" and seeing their media engagement activities as "using" media based on specific demand actions, thus making these needs get "satisfied". As the dissemination of intangible culture, it mainly considers the needs of the audience and spreads the culture of intangible cu

The colleges and universities are places of communication for non-legacy culture. In response, students are both the main body of communication and the audience. Therefore, how to combine the needs of students with the culture of non-legacy is the key to communication. Students are no longer passive subjects, but take the initiative to find information and discovery information, so they can use the online and offline activities of new media to spread the culture. Online WeChat 
and Weibo live broadcast as well as offline large-scale new media planning participation help students truly convert from audience to communication subject and mobilize the enthusiasm of them to participate in the editing and dissemination of non-legacy stories and craft skills through new media, thereby increasing the charm of the dissemination of intangible cultural heritage.

\section{CONCLUSION}

In short, in today's constantly updated network, the spread of intangible cultural heritage not only needs to work on the main body of communication, but also on the media. Moreover, it is necessary to consider the audience in the context of communication climate. Only through multipronged approach can we truly realize the long-term spread of intangible cultural heritage.

\section{References}

[1] Chang Ling: "Inquiring into the Digital Protection and Communication of Tibet's Intangible Cultural Heritage in the Context of New Media" [J], Journal of Southwest Minzu University (Humanities and Social Sciences Edition), 2010 (11).

[2] [United States] Negroponte. Digital Survival [M]. Haikou: Hainan Publishing House, 1997.

[3] Pei Zhanglong: "Development Trends and Countermeasures of WeChat Subscription in the Spread of Intangible Cultural Heritage" [J], Communication and Copyright, 2016(12). 